\title{
Being Human in the Age of the Brain: Models of Mind and Their Social Effects
}

\author{
Joseph E. Davis ${ }^{1}$ (D) Paul Scherz ${ }^{2}$
}

Accepted: 23 November 2021/Published online: 8 January 2022

(C) The Author(s), under exclusive licence to Springer Science+Business Media, LLC, part of Springer Nature 2021

The shimmering gold image presented in "Self Reflected" is not a real brain slice, but it sure looks like one. The computer-generated, hyperreal work of art, developed with a technique called reflective microetching, is the creation of neuroscientist Greg Dunn and applied physicist Brian Edwards. Designed to reflect light differently from different angles as you walk around it, the installation is also animated by multicolored lights that scan over the surface, suggesting how electric impulses might flow between neurons in different parts of the brain. What it offers, according to Dunn (n.d.), is "an unprecedented insight of the brain into itself." And what the brain is elucidating for us is not its physicality but "the nature of human consciousness ... what is occurring in our own minds as we observe this work of art." Self Reflected is "your brain perceiving itself." Hence, its title. A Wired article recommending the installation when it opened in Philadelphia suggested watching the teaser video and losing "yourself in a little self reflection" (Cole 2016).

The easy equation of self and brain has become so familiar we barely notice it. Neuroscientists have been claiming for years that the "age of the brain is upon us" (Frank 2009), an age in which the transition from a focus on "individual psychology to the chemistry and physics of the soul is in full swing ..." (Stone 1997:360). In

Joseph E. Davis

jed8m@virginia.edu

Paul Scherz

scherz@cua.edu

1 Institute for Advanced Studies in Culture, University of Virginia, 3 University Circle, Charlottesville, VA 22903, USA

2 School of Theology and Religious Studies, The Catholic University of America, 620 Michigan Ave, NE, Washington, DC 20064, USA 
our "emerging neurosociety" (Restak 2006), "brain science matters," according to Stanford neuroscientist, David Eagleman, in his book The Brain: The Story of You, because an understanding of the "strange computational material in our skulls" sheds light on "what we take to be real in our personal relationships and what we take to be necessary in our social policy: how we fight, why we love, what we accept as true, how we should educate, how we craft better social policy, and how to design our bodies for the centuries to come" (2015:1). The book is a companion to the PBS series, "The Brain with David Eagleman," which "explores the human brain in an epic series that reveals the ultimate story of us, why we feel and think the things we do" (PBS, n.d.). Such ultimate stories of us dot the bestseller lists.

Not that long ago, many experiential areas of human life were regarded as too subjective and unreliable for scientific research. In recent decades, however, a growing number of scientific disciplines concerned with cognition and the brainneuroscience, psychological science, biological psychiatry, behavioral genetics, psychogenetics, and more-have vigorously engaged subjects such as emotion, self, agency, and consciousness, and produced an exponentially growing research literature (LeDoux 2012:653; Klein 2012:363). The research in these fields is, in turn, giving rise to and informing a wide variety of ancillary programs - under neologisms such as neurolaw, neuromarketing, neuroaesthetics, and neuroeducation (see discussions in Farah 2012; Jones and Wagner 2020; Satel and Lilienfeld 2013). All these neuro fields and programs speak a vibrant language of discovery and of hope. They promise to have or soon have answers to critical questions about the mind and to tell us, like Eagleman purports to do, what makes us think, feel, desire, and act as we do.

The dominant explanatory strategy across these brain sciences is to account for conscious experience and human conduct by drawing on postulates and models from the natural sciences (Rose and Abi-Rached 2013). Following the principle that all of reality is physical, quantifiable, and describable from a third-person perspective has led much of this research toward a particular stance that is well captured by the neuroscience maxim that "the mind is what the brain does" (Minsky 1988; see Gazzaniga 2018; Pinker 1997). The proper objects of study are the neural states or computational functions that correlate with mental phenomena. Emotions are understood in terms of neurochemicals, thinking is conceptualized as "information processing," and neuroimaging is presented as revealing the location of the brain activity that supports modules of mind. By this reduction, mind, self, and experience can be rendered in conceptual structures that more easily yield to observable measurement and are more (ostensibly) tractable for scientific objectification on an idealized model of physical science.

It would be one thing if such claims for mechanistic and reductionist models of mind were confined to the lab and only pragmatically adopted as research tools for the sake of holding some aspects of human complexity constant. But, of course, they are not. Far from it. Contributors to the brain sciences have aggressively sought an audience among the general public. In popular books, we learn "how the brain creates our mental world" (Frith 2013), "how our emotions are made" (Barrett 2017), "how our brains become who we are" (LeDoux 2002), and "what makes us good or evil" (Zak 2012). We are told what happens in the brain when we love 
(Zeki 2008), hate (Freeman 2014), and have spiritual experiences (Newberg and Waldman 2016). We are given new "brain-based" tools to address vexing problems in education (Jensen 2008), parenting (Hughes and Baylin 2012), law (Hirstein et al. 2018), and business (Pillay 2011). We are provided with new strategies to enhance our brains ranging from special diets and nutrition supplements to self-help books on "changing" or "retraining" the brain (Amen 2015). We discover that whole social categories have different brains, including teenagers (Jensen and Nutt 2015), criminals (Fallon 2014), and the addicted (Kuhar 2012).

In their extensive popular writings, these neuro-researchers often carry on what can only be described as a polemic against the mind, against the natural attitude and what they often derisively call folk psychology. "Everything you thought you knew about ... [emotion or self or desire] ... is wrong" is a common refrain. To drive home the seeming radicalness, the claims are often expressed in a deflationary, debunking rhetoric, demanding that we muster the courage and honesty to recognize the illusory character of our self-conception as persons with minds and reason and free will. In their popular advocacy, researchers drop much of the context, limitations, and qualifications of findings that researchers report in scientific articles. They replace caution with confident assertions of revolutionary breakthroughs mixed with self-help applications and recommendations for the design of social programs (Odendaal, Levänen, and Westerlund 2018).

Further and critically, the explanatory strategy has been shaped by and grown up in a feedback relationship with neuro-technologies. These range from neuroimaging machines and electroencephalographs (EEG) to psychotropic drugs like Prozac and brain devices that use electricity, magnetism, or light-and-sound pulses to change brainwave frequencies (Brenninkmeijer 2010). These ubiquitous technologies have helped give brain science a certain cultural and epistemic authority and drawn the attention of philosophers and bioethicists concerned with the possible forms they might take and consequences they might have in society, social policy, clinical practice, and the lives of ordinary people. Much of this work, however, tends to be more speculative and prospective than concrete (Vrecko 2010).

Yet the influence of the brain sciences is not new, nor incidental to the science. The study of molecular malfunctions in neurotransmission, for instance, goes back to the 1950s and has been central to psychopharmacology and the progressive reconceptualization of disorders, once conceived as "mental" and involving the psyche, as "brain diseases" (Healy 1997; Whooley 2019). Empirical work in the social sciences and humanities has explored the growing influence of neuroscience in society. Studies, for instance, have found strong public belief in neurochemical accounts of common disorders and drug specificity of action (Carpenter-Song 2009; Davis 2020; Monterosso and Schwartz. 2020). They have demonstrated how people find neuroimaging visually appealing and transparent (Dumit 2004; Joyce 2008), and actively use brain devices as technologies of the self (Brenninkmeijer 2010). They have shown that the public attributes greater scientific objectivity and truth to brain images and reductive explanations than to other types of information about the mind (e.g., Fernandez-Duque et al. 2015; Hopkins et al. 2016; Weisberg, Taylor, and Hopkins 2015; review in Thornton 2011). 
A first goal of this special issue is to contribute to the literature on social effects, asking how neuro research has been popularized and deployed in wider domains of culture and how these efforts of translation have altered institutions and popular self-understandings. What are the effects of using these models of mind, we ask, in education, psychiatric care, medicine, and other fields? The second, and interrelated goal, is to consider their theoretical and methodological adequacy to the mental phenomena ostensibly under study and thus also to their real-world applications.

While a narrow reductionist stance toward the experiential dimension has been dominant, it is not without important challengers, questioning whether the assimilation of mental phenomena to biological mechanism is warranted (Klein 2016). Crucial developments in the sciences themselves suggest some new appreciation for the complexity of experience and the first-person perspective. The very turn to the study of phenomenal consciousness in the 1990s put the question of method on the table. The dominant naturalistic and functionalist approaches try to largely bypass first-person report and the qualitative character ("what it is like") of experience. But some scholars recognized early on the potential vacuity of this direction and called for renewed philosophical reflection and conceptual analysis as a starting point for thinking about conscious experience and subjectivity as a scientific question (e.g., Varela et al. 1991; Putnam 1999).

Some philosophers, for instance, working in the phenomenological tradition, challenged the standard model, common in the cognitive/brain sciences, of psychosocial correlation, in which conscious experience is conceptualized as an internal event within the mind-brain. They sought to articulate an approach to cognition that conceptualizes consciousness as "a complex set of capacities of embodied and situated agents" (Noë and Thompson 2004:18-19; Thompson and Varela 2001; Noë 2009). An embodied and socially embedded model of the human subject has been gaining steam over time while the computational/functionalist model of mind has been losing some of its luster (Gallagher and Zahavi 2012:5). A wide range of work on such topics as self (Midgley 2014), emotion (Fuchs 2013), psychopathology (Aho 2019; Sass et al. 2011), and much more has moved in this direction.

Phenomenological reconceptualization opens up the question of what a successful naturalization would actually entail. It does not imply any doubt that our consciousness is causally dependent on states of the brain, nor does such rethinking indicate that the mind cannot or should not be studied scientifically. But it does recognize that the social nature of human existence and the first-person, qualitative aspect of experience pose very difficult conceptual and methodological problems (Klein 2015). A science must be adequate to the "phenomena" under study in all its complexity, even if methodologically inconvenient. The brain sciences must accord conscious subjects and mental reality an irreducible place, otherwise investigations will rob subjectively given states and domains of experience of those intrinsic qualities that make them the experiences that they are and will obscure or deny the intersubjective way that we meet the world as a horizon of meaning that must be interpreted. This question of adequacy to the phenomena becomes especially critical as these research programs, often encoding biological differences, are translated into initiatives that, directly or indirectly, 
"change," to quote the neurologist Richard Restak (2006), "how we live, work, and love."

\section{The Papers}

This special issue began as a symposium, in February 2020, sponsored by the Picturing the Human working group of the Institute for Advanced Studies in Culture at the University of Virginia. Models of mind bear fundamentally on our understanding of ourselves and the social world, and our aim was to explore how the mechanistic language of cognitive/brain science and the practices associated with it are playing out in contemporary society. What makes this talk appealing? What types of consequences is it having for self-understanding and specific normalizing practices? Do the models provide a logical and theoretically warranted framework for the subject matter in question? Where would a more adequate direction have to go? Might alternative philosophical understandings and crosscultural comparisons provide some important clues? These were the organizing questions, and they inform the seven papers presented here.

In "Idea Technology and Ideology," Barry Schwartz provides a theoretical overview of the problems posed by translating theories from the human sciences into the public domain. He argues that social sciences, like psychology, have different public roles from physical sciences because they can affect how institutions and individuals understand the world and themselves through what Schwartz calls "idea technologies." This subtle influence, which is often little noticed, creates powerful looping effects that can undermine the scientific dialectic between theory and data, between ordering the facts and being accountable to them. Idea technologies can nudge people, via specific dynamics, into acting in ways that align with the theory, so justifying the theory even when it is false, when it is ideology. Psychology, he argues, increasingly dominated by neuroscience and genetics, is now shifting public conceptions of human actions toward ones founded in neuro-causation; it is making true what in fact may be ideology.

The next two papers explore the work of scientists and practitioners to translate neuroscientific ideas in the field of education. Suparna Choudhury and William Wannyn, in "Politics of Plasticity: Implications of the New Science of the "Teen Brain' for Education," chronicle the growing appeal and rapid expansion of "brainbased learning," beginning with enthusiasm for playing classical music to babies to the pervasive use of the concept of neuroplasticity in the high school curricula. Despite a growing endorsement of a more interactive account of brain and environment in the scientific literature, the translation of developmental brain science to the educational curriculum has centered on promoting "neuronal selfhood" and "self-regulation" of emotions and impulses. The popularity of this scientifically controversial approach may be due to its highly individualized conceptualization of the self and the enabling role of plasticity, interpreted as both a natural condition - a seemingly visualizable promise of limitless potential — and an acquired competence. Under the concept of plasticity, neuroeducation joins a rhetoric of hope and change to a pedagogy of learned techniques of self-regulation 
and self-monitoring. And by situating learning "inside" students, it effectively precludes attention to the social context in shaping the developing child.

Paul Scherz's article, "Life as an Intelligence Test: Intelligence, Education, and Behavioral Genetics," traces how researchers are encouraging the importation of the similarly controversial field of behavioral genetics into education policy. Behavioral geneticists promise better educational management through developing technologies that predict educational outcomes for individual students by analyzing the students' genes for their contribution to traits such as intelligence, as measured by intelligence tests. However, behavioral genetics falls under the long shadow of previous attempts to shape society through knowledge of hereditary traits, such as eugenics and sociobiology. As with these previous programs, it too subscribes to a highly individualistic and competitive vision of society in which intelligence is the decisive trait in the struggle for achievement. Not only is this vision inadequate to our intrinsically social nature, Scherz argues, but it also fails to accurately describe human intelligence. In behavioral genetics, intelligence is conceived in terms of mechanistic metaphors and computational models of mind that equate thinking with speedy problem-solving of the kind that IQ tests measure. Any richer understanding of intelligence in terms of expertise or engagement with meaning is occluded. The growing practical importance of these tests, both classical IQ tests and new genetic tests, threatens to foreclose other possibilities for more generative forms of education.

The issue of foreclosed possibilities is also a central concern of the next two articles, which address psychic suffering and addiction. Whereas the prior papers explore the impact of neuroscientific models on experts and institutional policy, Joseph Davis, in “'The Explanation You Have Been Looking For': Neurobiology as Promise and Hermeneutic Closure," investigates how neurobiological notions have reshaped lay understandings of their mental suffering. Although the "chemical imbalance" model of depression and other mood disorders has largely been discredited in the research community, Davis shows, based on interviews, that it pervades patients' understanding of their diagnosed condition. Despite claims to the contrary, psychiatrists and other doctors speak this language, and people also encounter it elsewhere in the popular media and direct-to-consumer drug advertising, sources which share the same assumptions about what is "real" and what strips people of their agency. While locating the cause of suffering in an internal biological mechanism seems to promise an explanation, this, Davis argues, is just what it does not do. Rather, it often traps people in a mechanistic model of themselves, cutting off from interpretation the very sources of experience and engagement that make sense-making possible.

In "Not You: Addiction, Relapse, and Release in Uganda," China Scherz, George Mpanga, and Sarah Namirembe find a similar dynamic at play around the chronic relapsing brain disease model of addiction. This model, dominant in medical discourse since the 1990s, sees addiction as an attribute of the person's brain that cannot be overcome. Though addicts may manage their harmful behavior, they are always at risk of relapse. The authors demonstrate the limitations of the disease model by exploring alternative understandings drawn from practitioners of Ugandan traditional religion and Pentecostalism. For practitioners of these 
alternative models, problem drinking is directly influenced by external spiritual others: lubaale spirits or demons. Taking a porous view of the self and encouraging steps to address the spiritual forces at work, these religious therapeutic systems are directed to a release from addiction and entry into new forms of social relationship, either with ancestral spirits or with Church communities. These are the very affordances, the authors argue, that the relapsing brain disease model forecloses.

The last two articles in this issue examine more deeply the adequacy of concepts and methodologies in psychological research. As William Hasselberger shows in "Laboratory Happiness or Human Flourishing: The Empirical Science of Wellbeing in Phenomenological Perspective," happiness has become a significant concern for public policy makers. Behavioral economists and positive psychologists are busy designing metrics to measure happiness and programs that seek to produce happiness through nudges. Happiness on this model is understood as an individualized, internal sensory state, a brain state in fact, and measured through self-reports or neuroimaging. Drawing on a phenomenological analysis of the experience of deep human goods, Hasselberger argues that this model and its accompanying methods of operationalization and measurement fundamentally misconstrue the place of meaningful and creative forms of activity in our lives and the nature of our flourishing.

Stan Klein, in "Psychological Theory and the Illusion of Scientific Prediction," goes further, pointedly questioning psychology's attempt to model itself as an objective and quantifiable form of science. This attempt has failed, Klein argues, on two levels. First, the drive toward quantification comes at the expense of the accurate description of mental phenomena, a scientifically unwarranted exclusion of the qualitative features of subjectivity and experience. Second, the standard way of testing psychological theories is inconsistent with the principles of scientific quantification. Changes introduced in psychological experiments do not lead to predictable, measurable alterations in outcomes. Rather, they merely show rank order, if an effect is present or absent. From the "numbers" produced by such experiments, little can be inferred or predicted and so different "theories" and hypothesized mental mechanisms have proliferated because the grounds to discriminate between them are absent. It is these "theories" that are being communicated to an unsuspecting public, who assume their scientific validity, and that we find exercising considerable influence in public affairs.

The point of this collection is not to reject neuroscientific investigations but to extend the challenge, already initiated, to concepts and methods that make unwarranted reductions, subsume human capacities and mental life under biological mechanism, and make popular appeal to techniques and technologies of detached self-management. The goal is to contribute to a more adequate science. To a science that does not treat our actions and experience as sensory episodes but as expressions of our way of being in the world, embedded within, and open to, a meaningful and shared life-world. To research programs that recognize the inherently social and contextual elements of human action and understanding, and that acknowledge the necessary background of a culture and a history. To lines of study that engage, conceptually and methodologically, with the inescapably hermeneutic and phenomenological aspects of human life. We are not our brains, and only such a better 
science could help tell the "story of us" and inform social interventions in ways that are genuinely beneficial.

Acknowledgements We would like to thank the other participants and respondents at the 2020 symposium for their contributions and perceptive commentaries, including Ira Bashkow, Talbot Brewer, Jonathan Buttaci, Matthew Crawford, Eve Danziger, Howard Kaye, Tanya Luhrmann, Shabnam Mousavi, Justin Mutter, and Alva Noë. Support for the symposium was generously provided by the Issachar Fund.

\section{Declarations}

Conflict of interest The authors declare that they have no conflicts of interest.

Ethical Approval This article does not contain any studies with human participants or animals performed by the authors.

\section{References}

Aho, Kevin.

2019 Contexts of Suffering: A Heideggerian Approach to Psychopathology. Lanham, MD: Rowman and Littlefield.

Amen, Daniel G.

2015 Change Your Brain, Change Your Life: The Breakthrough Program for Conquering Anxiety, Depression, Obsessiveness, Lack of Focus, Anger, and Memory Problems. Revised and Expanded. New York: Harmony Books.

Barrett, Lisa Feldman

2017 How Emotions Are Made: The Secret Life of the Brain. New York: Houghton Mifflin Harcourt. Brenninkmeijer, Jonna

2010 Taking Care of One's Brain: How Manipulating the Brain Changes People's Selves. History of the Human Sciences 23:107-126.

Carpenter-Song, Elizabeth

2009 Children's Sense of Self in Relation to Clinical Processes: Portraits of Pharmaceutical Transformation. Ethos 37:257-281.

Cole, Brendan

2016 A Gold-Leaf Brain Lights Up with the Awesome Complexity of Neurons. Wired (June 24). https:// www.wired.com/2016/06/your-brain-as-art/

Davis, Joseph E.

2020 Chemically Imbalanced: Everyday Suffering, Medication, and Our Troubled Quest for SelfMastery. Chicago: University of Chicago Press.

Dumit, Joseph

2004 Picturing Personhood: Brain Scans and Biomedical Identity. Princeton: Princeton University Press.

Dunn, Greg.

n.d. "Self Reflected." https://www.gregadunn.com/self-reflected/ and "The Art and Concept of Self Reflected" "https://www.gregadunn.com/self-reflected/the-art-of-self-reflected/

Eagleman, David

2015 The Brain: The Story of You. New York: Pantheon.

Fallon, James

2014 The Psychopath Inside: A Neuroscientist's Personal Journey into the Dark Side of the Brain. New York: Portfolio.

Farah, Martha J.

2012 Neuroethics: The Ethical, Legal, and Societal Impact of Neuroscience. Annual Review of Psychology 63:571-591. 
Fernandez-Duque, Diego, Jessica Evans, Colton Christian, and Sara D. Hodges

2015 Superfluous Neuroscience Information Makes Explanations of Psychological Phenomena More Appealing. Journal of Cognitive Neuroscience 27: 926-944

Frank, Lone

2009 Mindfield: How Brain Science Is Changing Our World. Oxford: Oneworld Publications.

Freeman, Walter J.

2014 Societies of Brains: A Study in the Neuroscience of Love and Hate. New York: Psychology Press.

Frith, Chris

2013 Making Up the Mind: How the Brain Creates our Mental World. Malden, MA: Blackwell.

Fuchs, Thomas

2013 "The Phenomenology of Affectivity." In The Oxford Handbook of Philosophy and Psychiatry, edited by K.W.M. Fulford, Martin Davies, Richard G.T. Gipps, George Graham, John Z. Sadler, Giovanni Stanghellini, and Tim Thornton, pp. 612-631. New York: Oxford University Press.

Gallagher, Shaun, and Dan Zahavi

2012 The Phenomenological Mind. 2nd Edition. New York: Routledge.

Gazzaniga, Michael S.

2018 The Consciousness Instinct: Unraveling the Mystery of How the Brain Makes the Mind. New York: Farrar, Straus and Giroux.

Healy, David

1997 The Antidepressant Era. Cambridge, MA: Harvard University Press.

Hirstein, William, Katrina L. Sifferd, and Tyler K. Fagan

2018 Responsible Brains: Neuroscience, Law, and Human Culpability. Cambridge, MA: MIT Press.

Hughes, Daniel A., and Jonathan Baylin

2012 Brain-Based Parenting: The Neuroscience of Caregiving for Healthy Attachment. New York: W.W. Norton.

Hopkins, Emily J., Deena Skolnick Weisberg, and Jordan C.V. Taylor

2016 The Seductive Allure is a Reductive Allure: People Prefer Scientific Explanations that Contain Logically Irrelevant Reductive Information. Cognition 155:67-76.

Jensen, Eric

2008 Brain-Based Learning: The New Paradigm of Teaching. Thousand Oaks, CA: Sage.

Jensen, Frances E., and with Amy Ellis Nutt.

2015 The Teenage Brain: A Neuroscientist's Survival Guide to Raising Adolescents and Young Adults. New York: Harper.

Jones, Owen D. and Anthony D. Wagner

2020 "Law and Neuroscience: Progress, Promise, and Pitfalls." In The Cognitive Neurosciences, 6th ed., edited by David Poeppel, George R. Mangun, and. Michael S. Gazzaniga, pp. 1015-1026. Cambridge, MA: MIT Press.

Joyce, Kelly A.

2008 Magnetic Appeal: MRI and the Myth of Transparency. Ithaca, NY: Cornell University Press.

Klein, Stan B.

2015 A Defense of Experiential Realism: The Need to Take Phenomenological Reality on Its Own Terms in the Study of the Mind. Psychology of Consciousness: Theory, Research, and Practice 2:41-56.

Klein, Stanley B.

2012 'What is the Self?': Approaches to a Very Elusive Question. Social Cognition 30:363-366.

2016 The Unplanned Obsolescence of Psychological Science and an Argument for Its Revival. Psychology of Consciousness: Theory, Research, and Practice 3:357-379.

Kuhar, Michael

2012 The Addicted Brain: Why We Abuse Drugs, Alcohol, and Nicotine. Upper Saddle River, NJ: Pearson.

LeDoux, Joseph

2002 Synaptic Self: How Our Brains Become Who We Are. New York: Viking.

2012 Rethinking the Emotional Brain. Neuron 73:653-676.

Midgley, Mary

2014 Are You an Illusion? New York: Routledge. 
Minsky, Marvin

1988 The Society of Mind. New York: Simon and Schuster.

Monterosso, John, and Barry Schwartz

2020 Addiction Science and the Perception of Free Will. Journal for the Theory of Social Behavior 50:373-390.

Newberg, Andrew, and Mark Robert Waldman

2016 How Enlightenment Changes Your Brain: The New Science of Transformation. New York: Avery.

Noë, Alva

2009 Out of Our Heads: Why You Are Not Your Brain, and Other Lessons from the Biology of Consciousness. New York: Hill and Wang.

Noë, Alva, and Evan Thompson

2004 Are There Neural Correlates of Consciousness?. Journal of Consciousness Studies 11:3-28.

Odendaal, Albi, Sari Levänen, and Heidi Westerlund

2019 Lost in Translation? Neuroscientific Research, Advocacy, and the Claimed Transfer Benefits of Musical Practice. Music Education Research 21:4-19.

PBS.

n.d. "The Brain with David Eagleman." https://www.pbs.org/video/brain-david-eagleman-brain-davideagleman-preview/

Pillay, Srinivasan S.

2011 Your Brain and Business: The Neuroscience of Great Leaders. Upper Saddle River, NJ: Pearson.

Pinker, Steven

1997 How the Mind Works. New York: W.W. Norton.

Putnam, Hilary

1999 The Threefold Chord: Mind, Body, and World. New York: Columbia University Press.

Restak, Richard

2006 The Naked Brain: How the Emerging Neurosociety is Changing How We Live, Work, and Love. New York: Crown.

Rose, Nikolas, and Joelle M. Abi-Rached

2013 Neuro: The New Brain Sciences and the Management of the Mind. Princeton, NJ: Princeton University Press.

Sass, Louis, Josef Parnas, and Dan Zahavi

2011 Phenomenological Psychopathology and Schizophrenia: Contemporary Approaches and Misunderstandings. Philosophy, Psychiatry, and Psychology 18:1-23.

Satel, Sally, and Scott O. Lilienfeld

2013 Brainwashed: The Seductive Appeal of Mindless Neuroscience. New York: Basic Books.

Stone, Michael H.

1997 Healing the Mind: A History of Psychiatry from Antiquity to the Present. New York: W.W. Norton.

Thompson, Evan, and Francisco J. Varela

2001 Radical Embodiment: Neural Dynamics and Conscious Experience. Trends in Cognitive Sciences 5:418-425.

Thornton, Davi Johnson

2011 Brain Culture: Neuroscience and Popular Media. New Brunswick, NJ: Rutgers University Press.

Varela, Francisco J., Evan Thompson, and Eleanor Rosch

1991 The Embodied Mind: Cognitive Science and Human Experience. Cambridge, MA: MIT Press.

Vrecko, Scott

2010 Neuroscience, Power and Culture: An Introduction. History of the Human Sciences 23:1-10.

Weisberg, Deena Skolnick, Jordan C.V. Taylor, and Emily J. Hopkins

2015 Deconstructing the Seductive Allure of Neuroscience Explanations. Judgment and Decision Making 10:429-441.

Whooley, Owen

2019 On the Heels of Ignorance: Psychiatry and the Politics of Not Knowing. Chicago: University of Chicago Press.

Zak, Paul J.

2012 The Moral Molecule: The New Science of What Makes Us Good or Evil. New York: Bantam Books. 


\section{Zeki, Semir}

2008 Splendors and Miseries of the Brain: Love, Creativity, and the Quest for Human Happiness. Malden, MA: Wiley-Blackwell.

Publisher's Note Springer Nature remains neutral with regard to jurisdictional claims in published maps and institutional affiliations. 